\title{
SAÚDE MENTAL E O ENSINO SOBRE DROGAS NA GRADUAÇÃO EM ENFERMAGEM: AS METODOLOGIAS PARTICIPATIVAS
}

\author{
Mental health and the Teaching about Drugs in the \\ Graduatuon of Nursing: the Participative Methodologies \\ Salud Mental y la Enseñanza sobre Drogas en la \\ Graduación en Enfermería: las Metodologías Participativas
}

Elias Barbosa de Oliveira ${ }^{1}$

Celia Caldeira F. Kestenberg ${ }^{2}$

Alexandre Vicente da Silva ${ }^{3}$

\begin{abstract}
Resumo
Relato de experiência apresentado pelos professores da subárea Promovendo e Recuperando a Saúde Mental da Faculdade de Enfermagem da Universidade do Estado do Rio de Janeiro (FENF/UERJ). Realizamos um recorte temporal de 2001 quando a FENF/UERJ estabeleceu uma parceria com a Comissão Interamericana para o Controle do Abuso de Drogas (CICAD/ OEA) até 2006. A partir da parceria inicia-se na FENF/UERJ um processo de avaliação dos conteúdos, carga horária e metodologias adotadas no ensino sobre drogas. Como já trabalhávamos com conteúdos relativos ao tratamento, inserimos a abordagem preventiva com enfoque nas metodologias participativas. Conclui-se que há a necessidade de formar profissionais para lidar com a problemática das drogas como uma estratégia de ampliação da atuação e atenção à comunidade.
\end{abstract}

Palavras-chave: Enfermagem. Saúde Mental. Drogas llícitas. Currículo.

\section{Abstract}

Experience report presented by the professors of the field Promoting and Recovering the Mental Health of the Nursing College of the University of the State of Rio de Janeiro (FENF/ UERJ). We made a temporal cut from 2001 when the FENF/ UERJ established a partnership with the Inter American Commission for the Abuse of Drugs Control (CICAD/OEA) until 2006. From this partnership it begins in the FENF/UERJ a process of evaluation of the content, schedule and adopted methodologies in the teaching about drugs. Since we already had work with subjects related to the treatment, we insert the preventive approach focusing the participative methodologies. It was concluded that there is a necessity of to form professionals to deal with the problem of the drugs as a strategy to amplify the acting and attention to the community.

\section{Resumen}

Relato de experiencia presentado por los profesores del sub-área Promoviendo y Recuperando la Salud Mental, de la Facultad de Enfermería de la Universidad del Estado del Rio de Janeiro (FENF/UERJ). Hemos realizado un modelo histórico a partir de 2001 cuando la FENF/UERJ estableció un acuerdo con la Comisión Interamericana para el control del abuso de Drogas (CICAD/OEA) hasta 2006. A partir de esta asociación se inició en la FENF/UERJ un proceso de evaluación de los contenidos, horas y metodología utilizada en la enseñanza sobre drogas. Como ya habíamos trabajado con contenidos relativos al tratamiento, incluimos el abordaje preventivo con enfoque en las metodologías participativas. Concluimos que existe una necesidad de formar profesionales para afrontar la problemática de las drogas como una estrategia de ampliación de la actuación y atención a la comunidad.
Keywords:

Nursing. Mental Health. Street Drugs. Curriculum.
Palabras clave:

Enfermería. Salud Mental. Drogas llícitas. Curriculum 


\section{INTRODUÇÃO}

Estudos realizados dentro e fora do País ratificam a necessidade de introduzirmos a temática "drogas no ensino" na pesquisa e na assistência, devido à insuficiência de conhecimentos e habilidades referidas pelo enfermeiro para atuar junto ao indivíduo e família com história de abuso de álcool e outras drogas'.

Pensar a inserção do conteúdo sobre drogas no ensino de graduação em Enfermagem demanda do professor uma posição epistemológica no intuito de avaliar os determinantes sociais e históricos envolvidos nesta relação, as competências, as habilidades requeridas e os possíveis resultados. Neste sentido, faz-se necessária uma reflexão sobre os conhecimentos que a Enfermagem tem construído em uma área do saber tão distinta.

Ao longo de nossa trajetória, como professores da área de Saúde Mental e Psiquiatria, constatamos que estávamos diante da necessidade de avançarmos nas questões que diziam respeito aos conteúdos ministrados no ensino sobre drogas, à metodologia adotada e às práticas que se desenvolviam nos campos de estágio. Processo que ocorreu a partir de 2001, quando a Faculdade de Enfermagem da Universidade do Estado do Rio de Janeiro (FENF/UERJ), instituição onde trabalhamos, estabeleceu uma parceria com a Comissão Interamericana para o Controle do Abuso de Drogas (CICAD).

Com a parceria firmada, passamos a introduzir o tema drogas em seus aspectos preventivos do $1^{\circ}$ ao $6^{\circ}$ períodos de graduação, com exceção do $5^{\circ}$ período, em que não são ministrados conteúdos de Saúde Mental e Psiquiatria, e mantivemos os conteúdos relativos ao tratamento no $7^{\circ} \mathrm{e} 9^{\circ}$ períodos. Assim, ratificamos a necessidade da inclusão de conteúdo sobre álcool e drogas nos cursos de graduação de Enfermagem como condição fundamental para o enfermeiro poder exercer seu papel nesta área. Do ponto de vista da organização de serviços, o enfermeiro necessita de treinamento específico e contínuo para desenvolver as suas atividades em equipe multiprofissional de natureza institucional e extrainstitucional, envolvendo os enfoques preventivo e de tratamento?

A partir destas questões os objetivos que nos propomos com este relato de experiência foram: discutir a inserção do tema drogas na formação do enfermeiro com o enfoque nas medidas preventivas e de tratamento; ratificar a importância das metodologias participativas, dentre elas as dinâmicas de grupo.

\section{A prevenção pautada nas metodologias participativas}

0 problema do uso abusivo de substâncias psicoativas é considerado pela Organização Mundial de Saúde (OMS) grave problema de saúde pública. Entretanto, pouco se tem feito no campo da prevenção, definida como um processo de planejamento e implementação de múltiplas estratégias voltadas para a redução dos fatores de vulnerabilidade e riscos específicos e fortalecimento dos fatores de proteção ${ }^{3}$.

Assim, a prevenção primária ou universal visa evitar ou retardar a experimentação do uso de drogas pelo indivíduo. A prevenção secundária ou seletiva tem como objetivo atingir as pessoas que já experimentaram e que fazem uso ocasional de drogas, com intuito de evitar que o uso se torne nocivo, com possível evolução para a dependência. A prevenção terciária ou indicada é aplicada nos casos de tratamento devido ao uso nocivo ou à dependência, sendo necessário o encaminhamento para especialistas como uma forma preventiva de evitar danos maiores à saúde 4 .

As ações preventivas são urgentes, exigindo planejamento participativo, com base no conhecimento das condições de vida da população mediante levantamento diagnóstico e contatos intensos de familiarização. Em seguida, exigem seleção e capacitação adequadas dos educadores sociais e agentes de saúde, mobilização das lideranças detectadas, cooperação com organizações comunitárias existentes e Organizações Não Governamentais (ONGs), acompanhamento e avaliação das atividades a partir de metodologia participativa, considerada, internacionalmente, como a mais eficaz para implementar fatores de proteção contra a exposição aos diversos fatores de risco 5 .

As metodologias participativas visam respeitar valores, crenças, costumes, linguagem e tradições de cada grupo a quem destinamos as ações. Afinal, para se pensar a preven-ção é preciso pensar o indivíduo enquanto sujeito de seu ecossistema e estudar o equilíbrio possível entre os fatores de risco e os fatores protetores à sua saúde integral. Falar em fatores de risco e de proteção ligados ao uso/abuso das drogas é de suma importância, pois contribui para o entendimento e para uma ação efetiva em relação às possibilidades de prevenção ${ }^{6}$.

Por metodologias participativas de trabalho entendemos 0 emprego de métodos e técnicas que possibilitam aos integrantes de um grupo vivenciar seus sentimentos; perceber determinados fatos ou informações; refletir sobre eles; ressignificar seus conhecimentos e valores e perceber as possibilidades de mudanças. Tais metodologias pressupõem que atitudes e comportamentos em relação a qualquer tema ou fato da vida estão sempre associados aos conjuntos de valores, crenças, concepções, cognições e emoções que cada pessoa desenvolve em função de sua educação, ambiente familiar, cultural, nível sócio-cultural e econômico? ${ }^{7}$.

\section{METODOLOGIA}

Por constatarmos através de estudos que os enfermeiros se sentem pouco treinados ou capacitados em relação ao tema drogas ${ }^{8}$, o presente estudo tem caráter de um relato de experiência no intuito de contribuir com a área de Saúde Mental/Psiquiatria e demais disciplinas do currículo na construção de conhecimentos sobre drogas que ultrapassa as fronteiras do ensino formal.

Desenvolvemos o estudo no período de agosto de 2006 a julho de 2007, após apresentarmos a proposta do trabalho à Direção da FENF/UERJ e obtermos a autorização formal para a sua realização. Na coleta de dados, utilizamos como fonte os documentos da Comissão de Reestruturação do Currículo e os Programas da Subárea Saúde Mental e Psiquiatria da FENF/ UERJ. 0 recorte espacial da pesquisa ocorreu de 2001 a 2006.

Trata-se de uma Pesquisa-Ação cujo envolvimento do pesquisador na ação é parte integrante da pesquisa ${ }^{9}$, com abordagem qualitativa descritiva. Na coleta de dados utilizamos 
um instrumento com os seguintes itens: ano em que o tema drogas foi inserido na Subárea Saúde Mental e Psiquiatria, conteúdos ministrados sobre o tema, metodologia de ensino adotada e carga horária.

\section{RESULTADOS E DISCUSSÃO}

\section{A inserção dos conteúdos sobre drogas na subárea Saúde Mental e Psiquiatria}

A subárea Saúde Mental da FENF/UERJ está inserida na ampla Área Assistencial, que inclui os conhecimentos necessários à prática de assistência de Enfermagem individual e coletiva de acordo com o perfil epidemiológico traçado para a população/indivíduo a ser assistido. Ela acompanha praticamente toda a formação do graduando, com exceção do $5^{0}$ período, cujos conteúdos foram deslocados para o $7^{\circ}$ período. Conecta internamente seus vários temas, mas, em cada período, integra-se com os temas trabalhados nas demais subáreas.

Quanto aos conteúdos sobre drogas ministrados na subárea Saúde Mental, eles obedecem a uma lógica de conhecimentos organizados de forma complexa e crescente como parte dos saberes a serem adquiridos pelo aluno na saúde mental e nas demais áreas do currículo. Por se tratar de uma temática transversal, buscamos contextualizá-la no bojo da própria formação ao manter a interlocução com as demais áreas do currículo e despertar no aluno a capacidade de problematizar o fenômeno drogas na sociedade, tendo em vista os aspectos sociais, econômicos e políticos envolvidos.

Assim, do primeiro ao quarto períodos, não há uma aula cujo tema seja especificamente drogas; a questão é trazida pelo professor e alunos durante os encontros e se apresenta ao longo das discussões sobre os vários conteúdos abordados: percepção, autoconhecimento, crise, comunicação, família e outros.

No $1^{\circ}$ período, durante os seminários sobre paladar e olfato, os conteúdos sobre drogas como álcool e tabaco são trazidos pelo professor e alunos, mediante relatos de experiências, no intuito de se discutirem os aspectos sócioculturais relacionados às drogas, à busca pelo prazer e aos riscos envolvidos como as doenças orgânicas, os acidentes e as doenças sexualmente transmissíveis.

No $2^{\circ}$ período, trabalham-se a dinâmica familiar que se reflete no desenvolvimento da criança, crises da adolescência e ações em saúde mental que visam ao crescimento potencial de saúde da pessoa. 0 tema drogas é abordado, sendo discutidas as suas implicações nas relações familiares.

No $3^{\circ}$ período, ao analisarmos a intervenção em crise pelo enfermeiro, refletimos sobre alguns mecanismos de enfrentamento, nem sempre funcionais, adotados pelo indivíduo diante de crises do desenvolvimento e situacionais que podem envolver o uso e abuso de drogas.

Assim, algumas pessoas que não tiveram um desenvolvimento da personalidade que Ihes permita lidar razoavelmente bem com os fatores estressores da vida (ambientais e intrapsíquicos) recorrem, então, ao uso de substâncias como o álcool, barbitúricos ou maconha, que lhes possibilitam um distanciamento desses fatores. Outras pessoas tiveram experiências de vida que as levaram a perceber o mundo como ameaçador, não protetor. 0 uso de substâncias estimulantes como a cocaína e o crack permite então que elas se sintam fortes, potentes, em face desse mundo hostil ${ }^{10}$.

No $4^{\circ}$ período, trabalhamos as questões ligadas à visão psicossomática do homem. Neste momento são estudados 0 mecanismo da somatização e o processo multifatorial do adoecimento humano, destacando o estresse como principal fator de risco. São realizados debates e seminários sobre a relevância que o corpo psicossomático tem na sociedade atual. 0 conteúdo drogas é abordado como uma das conseqüências pela busca da saúde perfeita, sendo referidos os moduladores do apetite e os ansiolíticos, utilizados como forma de o indivíduo lidar com o estresse resultante das crenças e da cultura vigente.

No $6^{\circ}$ período, trabalhamos aspectos preventivos das drogas através de seminários com ênfase no papel do enfermeiro junto à família e grupos vulneráveis como as crianças, adolescentes e adultos jovens com história de uso e abuso de álcool e os problemas acarretados como as doenças sexualmente transmissíveis, a gravidez não planejada, a violência e os acidentes.

É na unidade familiar que ocorrem experiências, sejam elas de fracasso ou sucesso, saúde ou doença. No universo da família é que acontecem as trocas afetivas, marcantes para os indivíduos e decisórias no modo de ser e agir consigo mesmo e com os outros. Ela tem a responsabilidade na transmissão dos valores vigentes na sociedade e a função de cuidadora de seus membros, os quais convivem por afetividade, assumindo um compromisso de cuidado mútuo. Portanto, tem cabido à família 0 monitoramento e a supervisão em relação aos filhos para a percepção das expectativas e o cumprimento, ou não, das regras estabelecidas, fazendo com que se possibilite a proteção de associação a pares desviantes, minimizando a oportunidade de uso/abuso de drogas ${ }^{11}$.

No $7^{\circ}$ período, são ministrados conteúdos relativos ao tratamento do cliente e ao suporte à família, que possibilitam ao aluno desenvolver competências e habilidades no que diz respeito ao cuidado do cliente em acompanhamento ambulatorial ou hospitalar. Durante as aulas, discutimos temas como: estágios de mudança, voluntariado, grupos de auto-ajuda, manutenção da abstinência, fases de desintoxicação (retirada da substância), atendimento à família e a comunidade terapêutica como modelo de atendimento.

Estudos colocam em evidência a necessidade de investirmos na área da educação/formação dos enfermeiros para trabalharem os aspectos preventivos e de tratamento do indivíduo, família e grupos com problemas decorrentes do uso e abuso de álcool e outras drogas. No entanto, há evidências de atitudes negativas entre enfermeiros que se relacionam com usuários de drogas. Reconhecer as atitudes inapropriadas e refletir sobre o comportamento constitui o início de um processo de mudanças de atitude. 0 processo de avaliação das atitudes inclui reconhecer a sua origem, investigar como as mesmas afetam o cuidado dado do indivíduo e buscar 0 conhecimento através da educação formal ${ }^{12}$.

Neste sentido, procuramos aprofundar a discussão sobre o fenômeno drogas com enfoque na experiência subjetiva do aluno, 
tendo como princípios a percepção, a comunicação e o autoconhecimento, de maneira a trabalharmos crenças, valores e atitudes do grupo. Deste modo, esperamos que o aluno seja capaz de desenvolver a escuta, de conviver com o diferente, com o novo, e assumir uma atitude de respeito, de solidariedade, de confiança junto ao indivíduo e à família com história de uso e abuso de drogas.

0 que marca a diferença, nessa trajetória, é que antes ensinávamos a lidar com o outro, com a doença do outro. A partir da mudança passamos a ter como referência o eu, entendendo que é uma primeira etapa, fundamental para melhor compreender esse outro. Perceber os próprios sentimentos, sensações, emoções, pensamentos, implica darse conta de que as mazelas do outro também estão em si. E a partir do contato consigo mesmo, das descobertas de si, de sua subjetividade, o aluno vai se tornando apto para a escuta e o acolhimento do outro. Dessa maneira, vai construindo o seu conhecimento e não só absorvendo aquilo que está nos livros e foi construído pelos autores ${ }^{13}$.

Por avançarmos nos conceitos clássicos de abordagem do fenômeno drogas e nas metodologias de ensino, que incluem dinâmicas de grupos, diálogo circular, exposição de filmes, estudos clínicos e posterior debate, acreditamos na possibilidade de construção coletiva do conhecimento e na transformação da informação em atitudes que privilegiem o diálogo e o respeito às diferenças.

\section{Acolhendo, orientando e prevenindo 0 uso e abuso de drogas na comunidade}

Foi no bojo do movimento da integração docente assistencial que a Faculdade de Enfermagem da Universidade do Estado do Rio de Janeiro elaborou a estratégia de ensino teórico-prático na modalidade de internato. Esta modalidade permite ao aluno permanecer maior tempo nos campos de práticas com a finalidade de capacitá-lo para o planejamento, a execução, a supervisão e a avaliação da assistência de enfermagem, bem como desenvolver as atividades de educação e de pesquisa em ambulatórios, unidades de internação e centros de saúde ${ }^{14}$.

A subárea Assistencial II Promovendo e Recuperando a Saúde Mental, como parte integrante do internato, é desenvolvida nos $8^{\circ}$ e $9^{\circ}$ períodos em três cenários: no ambulatório, no hospital geral e na unidade de internação psiquiátrica.

No ambulatório, através da consulta de enfermagem em Saúde Mental, trabalho iniciado em 1996, docente e alunos realizam a acolhida dos usuários com história de hipertensão, doenças pulmonares, diabetes e outros agravos à saúde. Nas consultas, além de discutirmos os aspectos psicossomáticos envolvidos no processo saúde-doença, analisamos com a clientela os fatores protetores, tendo em vista os fatores de risco, dentre eles os associados ao uso/abuso de drogas como o álcool e o tabaco.

0 foco principal das reflexões sobre a história de vida do paciente é construir com o aluno a compreensão do significado que têm os eventos na vida dessa pessoa, não somente os sintomas ou a doença em si, mas eventos no cotidiano que podem se constituir em fatores de risco. A partir deste entendimento, o aluno é capaz de ajudar o paciente a dar-se conta que o processo saúde doença é multifatorial. Assim é possível, junto ao mesmo, encontrar estratégias adequadas para o enfrentamento de situações favorecedoras de agravos à saúde.

Na unidade de Doenças Infectoparasitárias, mantemos um espaço permanente de discussão da prática. Nestes encontros, em que utilizamos a dinâmica de grupo, trabalhamos a abordagem psicossocial do cliente convivendo com HIV/AIDS e as repercussões decorrentes da doença e da internação. Um dos objetivos do trabalho é dar o suporte em Saúde Mental ao aluno para que ele analise com os clientes os fatores de risco associados ao uso e abuso de drogas que expõem o indivíduo a doenças, dentre eles as sexualmente transmissíveis, como também a acidentes, ao envolvimento em situações de violência e agressão.

As discussões travadas visam à análise da história de vida dos clientes que vieram a adoecer em função da exposição aos fatores de risco e dos problemas acarretados, como uma estratégia de fortalecimento dos fatores protetores. Acreditamos que esta experiência, de estar com o outro e compartilhar as suas mazelas, contribua para a conscientização do aluno de sua própria vulnerabilidade, podendo potencializar mecanismos protetores em sua vida.

Em outro momento, no Núcleo de Estudos da Saúde do Adolescente, unidade que inclui ambulatórios e unidade de internação, os alunos, através de dinâmicas de grupo, desenvolvem atividades de prevenção e promoção da saúde relacionada ao uso/abuso de drogas e tratamento, tendo em vista a reconhecida vulnerabilidade da clientela.

No $9^{\circ}$ período, o aluno é inserido na unidade de psiquiatria, espaço que propicia a escuta, a reflexão e a aplicação dos conhecimentos adquiridos ao longo da formação, na relação direta com o cliente, a família e equipe. Cria-se a possibilidade de o graduando vivenciar, no dia-a-dia, o cuidado do cliente, tendo como princípio o diálogo, a interação e as trocas que se estabelecem com os demais técnicos de saúde mental.

Cabe enfatizar que, além de a unidade possuir clientes em sua maioria com transtornos mentais, inclusive decorrentes do abuso de drogas, há um espaço destinado ao tratamento daqueles com história de dependência química. No intuito de diversificar o atendimento, manter o vínculo do cliente/ família e prevenir as recaídas, há os dispositivos de atendimento de clientes externos como o Hospital-dia (HD) e o Ambulatório, onde são realizadas atividades como: recepção integrada, oficinas, consulta individual e em grupos, ampliando, deste modo, as diferentes formas de atendimento, antes centrado na internação/medicação.

Paralelo às atividades teóricas e práticas que os alunos do $8^{\circ}$ e $9^{\circ}$ períodos desenvolvem no internato, existe, desde 1990 , o projeto de extensão "Vivendo Vivências - tecnologia da sensibilização". Trata-se de um espaço formal na instituição de ensino onde o estudante expressa seus conflitos, medos, questionamentos e desencontros, mas também compartilha suas conquistas, vitórias e ratifica atitudes positivas. Objetivos: a) acolher as demandas emocionais dos alunos; b) ampliar o autoconhecimento do aluno; c) ampliar as habilidades interpessoais a fim de lidar de forma mais saudável com os eventos da vida e do cotidiano profissional; d) contribuir para a compreensão do Cuidar em Enfermagem como um Ato Humano. 
É adotado o trabalho de grupo por ser uma estratégia que possibilita a utilização de diversas técnicas que facilitam a compreensão de limites e possibilidades do ser humano e das forças que afetam as relações interpessoais.

A metodologia busca atingir os objetivos do projeto de forma proces-sual. Assim sendo, dividimos os encontros semestrais em três momentos: 1) eu; 2) eu e o outro; 3) nós. No primeiro, procuramos trazer cada participante à autoconsciência, à reflexão sobre o compromisso de estar participando de um grupo, à percepção de si mesmo enquanto ser humano. Temas principais são a percepção, autoconsciência, assertividade. No segundo momento, a tônica dos encontros se prende às diferenças e semelhanças existentes entre os seres humanos com as temáticas: conflito, empatia, compaixão, solidariedade dentre ouros. Cada participante vai tomando consciência desse fenômeno que 0 habilitará a identificar-se e diferenciar-se do outro. No terceiro momento, é abordada a interação entre as pessoas a partir do movimento identificatório de cada um.

Partimos do princípio de que, vivenciando suas questões, seus sentimentos e cognições, o aluno se aproxima do seu eu, o que é fundamental para a identificação das semelhanças e diferenças com o outro, o que, por sua vez, é importante para a aceitação dos valores, das crenças, das reações do outro, para a aproximação e o estabelecimento de trocas. Sem dúvida, habilidades essenciais na relação enfermeiro-paciente ${ }^{15}$.

\section{CONSIDERAÇÕES FINAIS}

Com as mudanças implementadas no currículo da FENF/ UERJ a partir de 1992 e a parceria firmada com a CICAD/OEA em 2001, que previa, dentre outras atividades, a inserção de conteúdos sobre drogas no ensino de graduação, sentimos a necessidade de reavaliar os conteúdos ministrados até aquele momento. Concluímos que o ensino deveria acompanhar as

\section{Referências}

1. Pillon SC, Luis MAV, Laranjeira R. Nurses'training on dealing with alcohol and drug abuse: a question of necessity. Rev. Hosp. Clín. Fac. Med 2003; 58 (2): 119 -24.

2. Ramos, LH; Pillon SC; Luiz MAV: Pedredi F: Laranjeira RR. 0 ensino sobre dependência química em cursos de graduação de enfermagem no Brasil, 1998. Rev. Acta Paul Enfermagem 2001; 14 (3): 35 - 43

3. Ministério da Saúde (BR). Secretaria Executiva. Secretaria de Atenção a Saúde. As políticas do Ministério da Saúde para a atenção aos usuários de álcool e outras drogas. Brasília (DF); 2003.

4. Cartana MHF, Santos SMA, Fenili RM, Spreicigo IS. Prevenção do uso de substâncias psicoativas. Texto\& Contexto Enferm 2004; 13 (2): 286-89.

5. Bucher R. Prevenindo contra as drogas e DST/AIDS: populações em situação de risco. Programa Nacional de DST/AIDS. Brasília (DF): Ministério da Saúde; 1995. mudanças ocorridas no país, no que se referiam as políticas públicas de enfrentamento das drogas calcadas no paradigma preventivo.

Como o fenômeno drogas é um problema de saúde pública, ratificamos a relevância da inserção dos conteúdos relativos à prevenção, com suporte das metodologias participativas, que propiciam a discussão e a análise dos aspectos psicossociais envolvidos em sua abordagem. Assim, ampliam-se as possibilidades de se trabalharem os valores, as crenças e as atitudes do aluno acerca do indivíduo e da família com história de uso e abuso de drogas, como uma das possibilidades de transformação da informação em ação.

No entanto, para transformamos a informação em ação, há necessidade de refletirmos sobre os saberes e as práticas de enfermagem. Devemos fazê-los em uma perspectiva humanística, criativa, imaginativa, e não baseada apenas em diagnósticos médicos ou de enfermagem. A categoria central da Enfermagem é o cuidar compreendido como processo dinâmico, mutável e inovador que implica o reconhecimento da singularidade e da subjetividade do usuário ${ }^{16}$.

Neste sentido, o currículo da FENF/UERJ, por sua integralidade, ou seja, que supera dicotomias como teoria/ prática, saber/fazer, aluno/professor, em busca da construção de um conhecimento crítico e socialmente determinado ${ }^{14}$, propiciou a inclusão de um tema que por sua transversalidade e atualidade nos impulsiona à conquista de novos espaços, novas práticas e novos saberes.

Para responder a este desafio, a Enfermagem, que vivencia de perto os problemas de saúde da população e representa o maior contingente de trabalhadores da saúde, tem pela frente uma grande responsabilidade: ampliar a sua participação nas políticas públicas de enfrentamento do fenômeno drogas na sociedade mediante o investimento na capacitação de recursos humanos nesta área do saber, de modo a avançar nas questões que dizem respeito à pesquisa, ao ensino e à assistência. ${ }^{17}$

6. Caldeira ZF. Prevenção ideal versus prevenção possível. In: Inem C, Baptista M. Toxicomanias: abordagem multidisciplinar. Rio de Janeiro (RJ): Sette Letras;1997.

7. Silva RC. Metodologias participativas para trabalhos de promoção de saúde e cidadania. São Paulo (SP): Vetor; 2002.

8. Barros MA, Pillon SC. 0 enfermeiro como integrante de uma equipe interdisciplinar na prevenção do primeiro uso de drogas. In: Luis MAV, Pillon SC, organizadores. Assistência a usuários de álcool e drogas no Estado de São Paulo: uma amostra de serviços e programas. Ribeirão Preto(SP): FIERP/USP; 2004.

9. Minayo MCS. 0 desafio do conhecimento: pesquisa qualitativa em saúde. $6^{\text {a }}$ ed. São Paulo (SP); Hucitec; 1999.

10. Rocha R. M. Enfermagem em saúde mental. $2^{\mathrm{a}}$ ed. Rio de Janeiro (RJ): Ed. Senac Nacional; 2005.

11. Schenkel M, Minayo MCS. A implicação da família no uso abusivo de drogas: uma revisão crítica. Rev Ciência e Saúde Coletiva, 2003; 8 (1): 299-306. 
12. Pillon SC, Laranjeira RR. Formal education and nurse's attitudes towards alcohol and alcoholism: brazilian sample. Medical Journal, São Paulo , 2005; 123 (4): 175-80.

13. Rocha RM, Kestenberg CCF, Oliveira EB, Silva AV, Nunes MBG. Construindo um conhecimento sensível em enfermagem. Rev. Bras Enferm, Brasília, 2003; 56 (4): 378-80.

14. Freire RP, Guimarães RM, Henriques RLM, Mauro MYC. 0 currículo integrado da Faculdade de Enfermagem UERJ: uma reflexão sobre a formação de recursos humanos para o SUS. Rev Bras Enferm 2003; 56 (4): 381-84.
15. Kestenberg CCF. 0 curador ferido: o paradoxo na arte de cuidar. Cad IPUB, Rio de Janeiro, 2000; 6 (19): 121-27.

16. Martins CM, Pillon SC. Análise do programa Saúde da Família e o uso de álcool e drogas. In: Luis MAV, Pillon SC. Pesquisas sobre a prática da assistência a usuários de álcool e drogas no Estado de São Paulo. Ribeirão Preto (SP): Fundação Instituto de Enfermagem de Ribeirão Preto; 2004.

17. Wrigth MGM. La profesión de enfermeria y el fenómeno de las drogas. In: Comissión Interamericana para el Controle del Abuso de Drogas / CICAD. Los Nuevos Programas de Doctorado en Enfermeria y su Contribución en la Reduión de la demanda de las Drogas en America Latina. Retos y Perspectivas. Washington, D.C, 2003. p. 43 -63. 